\title{
Work hubs \\ location considerations and opportunities for reduced travel
}

\author{
Anna Kramers \\ KTH Royal Institute of Technology \\ Environmental Strategies Research and Centre for \\ Sustainable Communications, Lindstedsvägen 5, SE-100 44, \\ Stockholm, Sweden \\ kramers@kth.se \\ Mattias Höjer \\ KTH Royal Institute of Technology \\ Environmental Strategies Research and Centre for \\ Sustainable Communications, Lindstedsvägen 5, SE-100 44, \\ Stockholm, Sweden \\ hojer@kth.se
}

\author{
Marcus Nyberg \\ Ericsson $\mathrm{AB}$ \\ User Experience Lab Ericsson Research, \\ Torshamnsgatan 23, SE-16483, \\ Stockholm, Sweden \\ Marcus.nyberg@ericsson.com
}

\author{
Malin Söderholm \\ Stockholm University, \\ SE-106 91 Stockholm, Sweden, \\ malin_soderholm@outlook.co
}

\begin{abstract}
Cities worldwide are suffering from congestion among public transport users and motorists. Mayors have set ambitious targets to reduce traffic and improve public transportation, while at the same time reducing energy use. This paper investigates the option of using flexible workplaces in local nodes within urban regions in order to transform transportation needs. The business characteristics of this type of flexible workplace and the driving forces and potential barriers in its establishment are examined in an interview study with existing hub owners. The results provide novel information on emerging technologies related to urban transportation solutions and highlight how ICT solutions can affect the accessibility and relevance of flexible workplaces and thereby support their energy reduction potential.
\end{abstract}

Keywords - flexible workplace, co-working hub, ICT, energy reduction, transport reduction, transport needs, travel planners

\section{INTRODUCTION}

The development of information and communication technologies (ICT) has made it possible to perform work at other places than at the conventional workplace, e.g. at cafés, libraries, hotel lobbies, co-working places or from home. This paper examines work organization in the information society and potential benefits from an environmental point of view. In his book "The Third Wave" Toffler [1] argues that telecommunication would relieve some of the pressure on cities. It could raise the quality of life, reduce pollution and make it less difficult to commute. Telecommunication affects the demand for, and supply of, transportation, and vice versa [2]. Making use of telecommunication instead of commuting can provide substantial energy savings, particularly for those with a long commute to work [2, 3]. However, it can also lead to an increase in leisure and recreational travel [3] and generate travel that would not have occurred otherwise, such as: (i) a desire to travel to participate in activities identified via ICT, (ii) the time saved being used to make other trips and (iii) dispersed residential and employment locations that result in longer trips [2]. According to Salomon [4], travel patterns will be modified rather than reduced and choices on the use of either travel or telecommunication will be based on the mode that proves most beneficial for the user. However, technology and people's ability to use technology is changing, which means that new opportunities for travel reductions may emerge [5]. Therefore, the idea of using ICT for reduced travel is still relevant.

The daily journeys and location of activities have changed over the last centuries. Human mobility patterns and the geographical spread of activities have substantially expanded compared with in the preindustrialized society. In a previous age, it was possible to perform almost all activities with very small transport distances. When the service society emerged, the different activities moved away from the home (Fig 1). In a study based on location of activities, two future scenarios were created (Fig 2) [5]. These scenarios show how the location of activities, especially work, could be changed by the use of ICT. In the scenario "IT-telework", work takes place at home on certain days and in a conventional office on other days. If work instead were located at a local node in the neighborhood, scenario "IT-node", the activities would be less dispersed, leading to less travel. With the introduction of mobile broadband and Wi-Fi hotspots, the opportunities to work anywhere have increased. A previous interview study with mobile workers found 
that they prefer to make use of different places with

L- Leisure
H- Home
S-Service

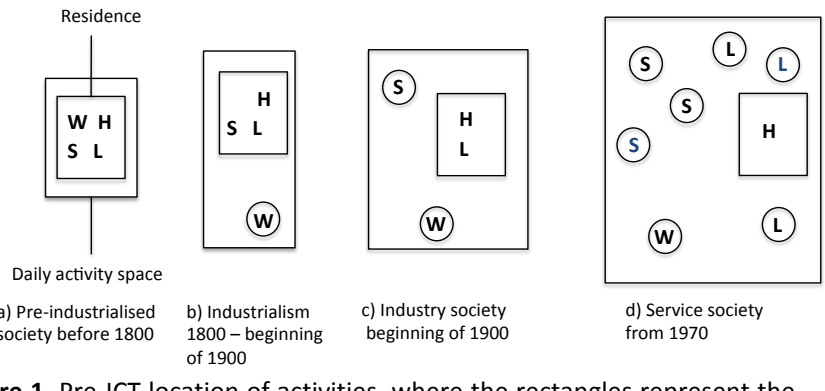

Figure 1. Pre-ICT location of activities, where the rectangles represent the size of the area within which an individual typically travelled daily (daily activity space). Years refer to Sweden's development [6].

different possibilities rather than working in homogeneous standardized workplaces [7]. The most important characteristic of the workplace was reported to be the people working there, because of the possibility to meet face-to-face. The second most important characteristic was found to be the office equipment.

Brown and O'Hara [7] claim that mobile work does not "take place", but "makes place" and transforms locations such as public and private transport vehicles, cafés, sites of leisure and offices. The mobile workers interviewed in that study arranged their activities within time to take advantage of the characteristics of places in which they found themselves.

There are a number of places where people can work today, but comprehensive information about availability, bookings and prices is lacking. In many city centers there are centrally located work hubs with flexible work opportunities, e.g. Spaces [8] in Amsterdam, United Spaces [9] in Stockholm and WeWork [10] in New York.

Locally, close to people's homes, there are places such as cafés, libraries and temporarily unused workplaces that can serve as flexible workplaces. A study by Kramers [11] found that available multimodal travel planners such as Rejseplanen [12], Trafiken.nu [13] and Transport Direct [14] provide no support for the activities "no trip" or "shorter journeys".

These systems could better support mobility management principles to reduce transport demand and optimize use of existing infrastructure if they could give information about available workplaces in the local neighborhood where people live[11]. In this paper we specifically look at how flexible location of workplaces could contribute to an urban structure requiring less travel, and how that could be supported by extended travel information systems. A starting point is the idea that next-generation multimodal travel information systems should be able to present, or at least be integrated with, information about available flexible workplaces.

L-Leisure

H- Home

S-Service

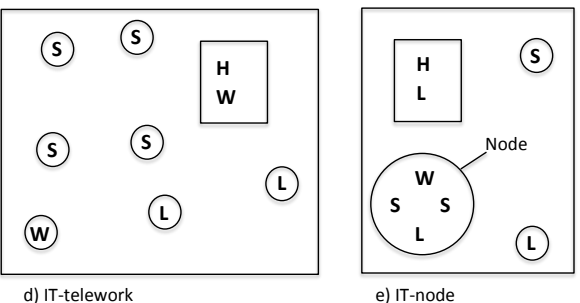

Figure 2. Two scenarios, the IT-telework and the IT-node, for location of activities in an ICT society before mobile broadband (Höjer, 2001).

By doing so, they could potentially encourage individuals to choose shorter journeys for work activities.

The aim of the study was to explore opportunities for more extensive implementation of work hubs in local nodes in urban regions and to illustrate how some emerging ICT-tools could be used to support the hubs. Moreover, the drivers and barriers to establishing a flexible workplace in a local node in an urban region were examined, the energy savings potential from reduced travel was illustrated and the role of ICT in increasing the use of flexible workplaces was explored.

\section{DEFINITIONS AND RESEARCH PROCESS}

\section{A. Definitions}

A delimitation of the study was that it focused on spaceindependent work $[15,16]$. This means e.g. that work which can be done at a desk or in an armchair was included, while work where a specific person needs to be at a specific location, e.g. most production work and many healthcare services, was excluded. Many jobs are a combination of space-dependent and spaceindependent work. For example, most teachers can carry out most of their planning independent of space, but they usually (so far) need be at a specific place when teaching. It is quite possible that the amount of space-independent work will increase in future, partly driven by ICT advances. In the remainder of this paper, the term "work" refers to space-independent work.

A new way of organizing work using multiple workplaces was developed here (Fig 3), from the scenarios proposed by Höjer [5]. It was then used to analyze the potential energy-saving effects as regards commuting. In the "Multiple workplace scenario", companies with a workforce performing spaceindependent work have their employees distributed over different workplaces, i.e. at home, in a local node or in a central node (Fig 3). The different node definitions used are adapted from Höjer [17], where a "local node" is a center with a mix of workplaces and housing and a 
"central node" is defined as the whole inner city.

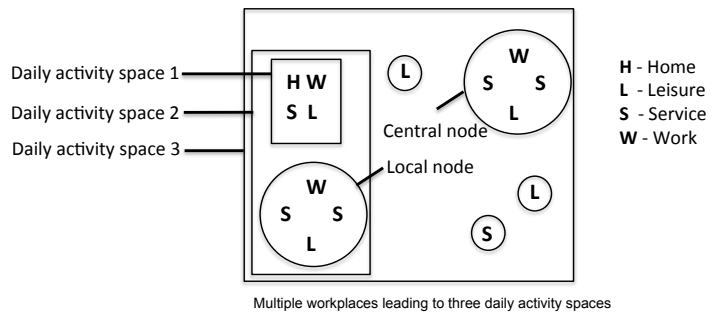

Figure 3. A new scenario for location of activities in an ICT-society.

Since the individual uses multiple workplaces during the week, this results in three different sizes of "the daily activity space" (Fig 3). The first daily activity space is where the individual chooses to work from home, and thus includes no travel.

The second daily activity space is where the individual chooses to work from a local node, leading to a shorter travel distance than today. The third daily activity space is where the individual works from a central node and the travel distance is at the same level as today. Thus, this is a combination of the two scenarios in Figure 2. Based on this model of multiple workplaces, some specific definitions are used throughout the paper (see Box 1).

Box 1: Definitions used in this paper.

\section{DEFINITIONS}

Node - an area where workplaces, services and leisure activities are gathered.

Central node - Nodes can be of different sizes. In principle, a traditional inner city can be seen as a large central node.

Local node - a node that is designed to serve primarily people living within walking or cycling distance.

Workplace - a place where it is possible to work, independent of the original purpose of the place.

Flexible workspace - a place where it is possible to use office space on demand.

Hub - a place dedicated to letting out places for work.

Local hub - a hub designed to serve primarily workers living within walking or cycling distance.

Local office - a local hub used exclusively by one company.

Organizations that offer flexible workspaces can be of different kinds. In Stockholm there are several actors that offer flexible workspaces (Table 1). There are office hotels that offer complete solutions for enterprises. Some of them offer complete solutions for enterprises. Others are co-working hubs - a specific type of office hotel offering a social community to their members. They arrange breakfast meetings, seminars, common pubs and parties to facilitate networking among their members.

Yet other actors let out temporary overcapacity to cover rent costs. Moreover, flexible workspaces can also be found at cafés, libraries, municipal buildings and hotel lobbies often offering free $\mathrm{Wi}-\mathrm{Fi}$.

\section{A. Research process}

This study looked upon various hub concepts and emerging supporting ICT-tools and used mainly two activities to identify those. The first was an interview study with existing hub owners which was used to explore the business characteristics of existing flexible workplaces and the potential driving forces and barriers to establish such workplaces in local nodes. It also included questions on how travel planners can inform users about available and bookable flexible workplaces. The second activity was a set of user-centered studies of emerging ICT-tools to be used to implement flexible workplaces.

\section{1) Interview study}

In the interview study, a number of work hubs were identified. Among them, five were selected for further study because: 1) they are located at different places in Greater Stockholm, 2) their business concepts include flexible working places and 3) their business concepts differ from each other. The selected organizations were (A) United Spaces [9] (B) Hub Stockholm [18], (C) Kolonien [19], (D) Coffice [20] and (E) Ekensbergskyrkan [21]. For a characterization of the organizations see Table 2.

An interview study with the owners of each organization identified was conducted in 2013. The interview questions were organized according to the Zachman framework [22], which includes questions about WHY the business is conducted, WHAT kind of business is conducted, HOW the business is conducted, WHERE the business is conducted, WHEN the business is conducted and WHO is conducting the business.

To get the organization owners' view on the driving forces and potential barriers to establishing a hub business in a local node and on presenting their service offering in a travel planner or other information system, five additional questions were included:

- What are the drivers to establishing a hub business in a local node?

- What are the potential barriers to establishing a hub business in a local node?

- What is your view on presenting your service offering in a travel planner?

- How are your services booked today? 
- Would your existing systems work with a travel planner?

TABLE 1. Categorisation of businesses offering flexible working places

\begin{tabular}{|c|c|c|c|c|}
\hline $\begin{array}{l}\text { Type of } \\
\text { business }\end{array}$ & $\begin{array}{c}\text { Enterprise with } \\
\text { overcapacity }\end{array}$ & $\begin{array}{c}\text { Conventional office } \\
\text { hotel }\end{array}$ & $\begin{array}{c}\text { Hub - office hotel } \\
\text { with social } \\
\text { community }\end{array}$ & Free workspaces \\
\hline Target group & Any company & $\begin{array}{l}\text { Small \& Medium } \\
\text { Enterprises (SME) }\end{array}$ & $\begin{array}{l}\text { Small \& Medium } \\
\text { Enterprises (SME) }\end{array}$ & Individuals \\
\hline Agreement type & Sublet & Rental & Membership & No agreement \\
\hline $\begin{array}{c}\text { Shortest } \\
\text { contract period }\end{array}$ & $\begin{array}{l}\text { Varying, often longer } \\
\text { periods }\end{array}$ & 3 months & 1-3 months & No contract \\
\hline Work areas & Conventional & Conventional & $\begin{array}{c}\text { Conventional and } \\
\text { activity-based }\end{array}$ & Activity-based \\
\hline
\end{tabular}

Some information was found on the organizations' websites and thus excluded from the interviews. The semi-structured interviews lasted for one hour and took place at the respective organization's office.

The interview study gave input to the part on hub concepts and on how extended travel planners could work as a supporting tool to work hubs.

\section{2) User-centred studies}

The user-centered studies were performed by Ericsson and investigated emerging technologies that can support cities within the transportation domain. From this, promising ICT opportunities were identified and explored through a mixture of methods, all based on established practices for human-centered research and innovation [23]. The studies can roughly be divided into three categories: 1) Challenges faced by cities around the world, 2) User-centered concept development, and 3) ICT and big data opportunities.

The first category concerned the challenges large cities face, and explorations of how ICT can be used to address them [24]. The methods used included literature studies, interviews with researchers and city planners, and field research and observations. The outcome of this work provided a baseline for the continued work around more specific ICT topics.

The second category explored various communication concepts for a more contextual form of remote collaboration, given different situations and activities [25]. One of the ideas was to enable remote experiences and shared contexts for a variety of collaboration scenarios. The methods used included focus groups, indepth interviews; home visits with Swedish interviewees, and design mock-ups. opportunities around mobility in cities. One case example is the use of real-time analysis of human mobility with data gathered from mobile networks and app usage, to improve both planning of public transportation and journey recommendations to individuals [26, 27]. The work included creation of proof-of-concepts and technical tests of functional components.

\section{HUB CONCEPTS}

In this section, the results from the interview study with the owners of the different hub organizations are presented. These results concern how they viewed the basic idea of a work hub, what they saw as their service offering, and how they reasoned regarding location.

\section{A. The idea of establishing flexible workplaces}

For three of the organizations surveyed (A, B, C), the main idea with establishing a hub was to offer a flexible and central working place that included an arena for learning, exchange and networking for small and medium enterprises. One of the organizations (E) wanted to create an open community for students and jobseekers in its neighborhood. Two of the organizations $(\mathrm{B}, \mathrm{C})$ wanted to co-locate businesses within the same sector. Through co-location, it is possible for different firms to interact and be inspired by each other. The sectors represented today in the organizations surveyed are social entrepreneurs, design, media and communication firms, and small and medium consultancy firms. There are also freelancers, researchers and journalists among the members.

One organization (D) uses its business to explore how individuals want to work from an architectural and socio-economic perspective. The architectural perspective is used to explore interaction between 
spaces with different accessibility for different categories of membership in its office. These spaces are private, semi-public or public. The private space is only accessible by the owner of the organization. The semipublic space is an open area between the private and the public space where members have priority access to desks. In the public space, anyone is welcome. The socio-economic perspective is used to understand how members with different socio-economic conditions interact. The members are from large established companies and public authorities, but could also be students, freelancers or small business owners.

\section{B. Business characteristics and service offering}

The business characteristics and service offerings of the organizations surveyed are summarized in Table 2 . The hub business idea involves the hub signing a long-term contract with the owner of the building and offering shorter periods of rental to smaller firms with more flexible conditions. Three of the organizations (A, B, C) require membership by firms before granting them access to the workspaces. The membership period varies between 3 months and one year. The business idea of the enterprises $(D, E)$ offering free workspaces is based on the assumption that their primary business will gain from offering free workplaces to the general public. For example, by offering free workplaces they sell more coffee in the case of the café, while the church is able to reach out to more people.

Four of the organizations (A, B, C, D) offer different sizes of meeting rooms, which are available for rent to non-members. The monthly cost for the different service offerings was categorized here as Low $(<€ 250)$, Medium (€250-350) and High ( $€ 350)$.

\section{Location is critical}

The organizations surveyed only have one physical location in Greater Stockholm. There are multiple reasons for their location choices. One reason is to make it easy for members to pass by and stop for a short period between different meetings. Another is to make it possible for members to invite customers and partners to meetings at a central place in the city center. Three of the organizations (A, B, D) are located in the city center of Stockholm, within close proximity to public transportation since there are no or very limited possibilities to park a car close to the office.

The possibility to gather a critical mass of companies within a specific industry is also a reason for locating in a certain place. One organization (C) has placed its office close to an established cluster of companies in the industry segment it targets (media, design and communication). Another organization (B) is placed in the city center in order to reach a sufficiently large number of companies of the industry segment targeted (social entrepreneurs) within the area.
Locating the organization $(\mathrm{D}, \mathrm{E})$ in a housing area to offer flexible workplace solutions to the people living in the neighborhood is an additional consideration. One of the organizations (D) surveyed is located on a corner at street level in a neighborhood in the City of Stockholm, which makes it easy for people who live there to stop by. Another (E) is located in a church building that is centrally located in a suburb of Stockholm.

\section{Location of hubs in local nodes, barriers and drivers}

With a few exceptions, flexible workplace as a service is only available in central areas of Greater Stockholm. There are many different stakeholder perspectives connected to this type of business, the stakeholders mentioned during the interviews being: The workers who will use the service, the organizations that establish and operate the service, the society represented by the municipalities. These three categories are used below in a presentation of the hub owners' thoughts on driving forces and barriers for establishing local hubs.

\section{1) Driving forces \\ The workers}

The main motive for workers to work from a hub is to get access to the workplace and its different services (A, $\mathrm{B}, \mathrm{C})$. Another motive is to become part of a community where new knowledge, exchange and networks are created. If the hub were to be located near the residential area, the workers would save time, money and the environment by reducing their travel (A, D).

\section{The organizations}

The driving force for businesses that want to establish flexible workplaces is mainly commercial, i.e. to establish a profitable business (A, E). However, the experience from companies working within the hub business today shows that it takes a substantial amount of time (5-10 years) to establish an economically viable activity (A). One possibility is to combine the hub business with another income-generating activity, such as café, lunch restaurant, sports facility etc. (D).

In order to attract customers to a hub in a local node, added value is required. By also providing access to a hub in a central node, the hub business could make the service offering to its members more complete (A, C). The members would then have access to a centrally located hub with possibilities to meet customers and partners from other places and at the same time have access to a local hub to do daily work that did not require face-to-face meetings. In this way, valuable services could be created with less resources than would otherwise be needed (A).

There are areas in the suburbs of Stockholm where a certain type of company has gathered in clusters, which makes it easy to establish a hub there. 
An example is the city district Hägersten, where many creative design-orientated companies have formed a

TABLE 2. Type of business (according to the definitions used in

Table I) carried out by the organisations surveyed and their service offering

\begin{tabular}{|c|c|c|c|c|c|}
\hline \multicolumn{6}{|c|}{ (C). } \\
\hline Organisation & Coffice & $\begin{array}{l}\text { Ekensberg } \\
\text { Church }\end{array}$ & Kolonien & HubStockholm & $\begin{array}{l}\text { United } \\
\text { Spaces }\end{array}$ \\
\hline $\begin{array}{c}\text { Type of } \\
\text { Business }\end{array}$ & $\begin{array}{c}\text { Free } \\
\text { workspaces }\end{array}$ & $\begin{array}{c}\text { Free } \\
\text { workspaces }\end{array}$ & $\begin{array}{c}\text { Hub - } \\
\text { office hotel } \\
\text { with social } \\
\text { community }\end{array}$ & $\begin{array}{c}\text { Hub - office } \\
\text { hotel with } \\
\text { social } \\
\text { community }\end{array}$ & $\begin{array}{c}\text { Hub - office } \\
\text { hotel with } \\
\text { social } \\
\text { community }\end{array}$ \\
\hline $\begin{array}{c}\text { Rental of } \\
\text { meeting } \\
\text { room }\end{array}$ & $\begin{array}{l}\text { Yes, open to } \\
\text { public }\end{array}$ & No & $\begin{array}{l}\text { Yes, open } \\
\text { to public }\end{array}$ & $\begin{array}{l}\text { Yes, open to } \\
\text { public }\end{array}$ & $\begin{array}{l}\text { Yes, open to } \\
\text { public }\end{array}$ \\
\hline Membership & $\begin{array}{l}\text { Required for } \\
\text { level } 2\end{array}$ & $\begin{array}{l}\text { Not } \\
\text { required - } \\
\text { Open to } \\
\text { public }\end{array}$ & Required & Required & Required \\
\hline $\begin{array}{c}\text { Service } \\
\text { offering } \\
\text { level } 1\end{array}$ & $\begin{array}{l}\text { Small desk in } \\
\text { café } \\
\text { environment, } \\
\text { armchairs, } \\
\text { window } \\
\text { spaces. Cost: } \\
\text { none }\end{array}$ & $\begin{array}{c}\text { Access to } \\
\text { table or } \\
\text { desk in } \\
\text { open office. } \\
\text { Cost: none }\end{array}$ & $\begin{array}{l}\text { "Flexible free- } \\
\text { lance space" } \\
\text { Unlimited } \\
\text { access to } \\
\text { drop-in } \\
\text { flexible } \\
\text { desk. Cost: } \\
\text { low }\end{array}$ & $\begin{array}{c}\text { "Hub } \\
\text { Connection" Part } \\
\text { of the } \\
\text { community, } \\
\text { access to } \\
\text { events, can } \\
\text { rent a desk. } \\
\text { Cost: low }\end{array}$ & $\begin{array}{c}\text { "Business } \\
\text { Lounge" } \\
8 \\
\text { hours/month } \\
\text { Chair in the } \\
\text { lounge and } \\
\text { coffee. Cost: } \\
\text { medium }\end{array}$ \\
\hline $\begin{array}{c}\text { Service } \\
\text { offering } \\
\text { level } 2\end{array}$ & $\begin{array}{c}\text { Priority } \\
\text { access to } \\
\text { desk in open } \\
\text { office, } \\
\text { kitchenette } \\
\text { \& printer } \\
\text { Cost: low }\end{array}$ & & $\begin{array}{l}\text { "Permanent } \\
\text { freelance } \\
\text { space" } \\
\text { Unlimited } \\
\text { access to a } \\
\text { permanent } \\
\text { desk. Cost: } \\
\text { low }\end{array}$ & $\begin{array}{c}\text { "Hub Lite" } \\
25 \text { hours per } \\
\text { month } \\
\text { desk in open } \\
\text { office } \\
\text { Cost: low }\end{array}$ & $\begin{array}{c}\text { "Business } \\
\text { Lounge } \\
\text { Premium" } 24 / 7 \\
\text { desk \& } \\
\text { cupboard in } \\
\text { open office } \\
\text { Cost: high }\end{array}$ \\
\hline $\begin{array}{c}\text { Service } \\
\text { offering } \\
\text { level } 3\end{array}$ & & & $\begin{array}{c}\text { "Shared } \\
\text { room" } \\
\text { Share a } \\
\text { permanent } \\
\text { room } \\
\text { Cost: } \\
\text { medium } \\
\end{array}$ & $\begin{array}{c}\text { "Hub Casual" } \\
50 \text { hours per } \\
\text { month } \\
\text { desk in open } \\
\text { office } \\
\text { Cost: medium }\end{array}$ & $\begin{array}{c}\text { "Private Office" } \\
24 / 7 \text { access to } \\
\text { own private } \\
\text { office } \\
\text { Cost: high }\end{array}$ \\
\hline $\begin{array}{c}\text { Service } \\
\text { offering } \\
\text { level } 4\end{array}$ & & & $\begin{array}{l}\text { "Own room" } \\
\text { An own } \\
\text { permanent } \\
\text { room. Cost: } \\
\text { high }\end{array}$ & $\begin{array}{c}\text { "Hub Frequent } \\
100 \text { hours per } \\
\text { month } \\
\text { desk in open } \\
\text { office } \\
\text { Cost: medium }\end{array}$ & \\
\hline $\begin{array}{c}\text { Service } \\
\text { offering } \\
\text { level } 5\end{array}$ & & & & $\begin{array}{l}\text { "Hub Local" } \\
\text { Unlimited } \\
\text { access to } \\
\text { own desk. } \\
\text { Cost: high }\end{array}$ & \\
\hline
\end{tabular}

cluster. Initially, they located there because they could not afford space in the city center (C). Many companies thought at first that it would be a disadvantage to be located together with their competitors, but over time co-location has proved to be beneficial for the companies, since it has led to more co-operation and business rather than exclusion and negative competition

\section{The society}

An incentive for a municipality to establish flexible workplaces near a residential area is to reduce commuting and encourage people to walk or cycle to work (E). Providing flexible workplaces by creating a hub in a local node can also have a positive impact on 
society. Workplaces can be offered in libraries and other public buildings. A hub located in a local node can become a new kind of local community center (B). There are municipalities in the Greater Stockholm area that are already discussing the possibility of combining libraries and job centers with flexible workplaces (B, D).

\section{2) Potential barriers}

\section{The workers}

One of the interviewees (E) claimed that one of the main barriers is people themselves, who are changeaverse and may have difficulties in thinking and doing things differently from usual. That interviewee also argued that going to work is a fundamental human habit.

\section{The organizations}

There are financial barriers to companies that want to establish a hub in a local node. A business will not necessarily be profitable in a local node just because it is profitable in a central node. The willingness to pay for office space is significantly lower in the suburbs and therefore the possible income for a hub business is lower (A).

There are also companies who offer their unused workplaces for rent, both in the suburbs and in the center of Stockholm (A). The availability of these workspaces is random and they may cost significantly less than the workspaces offered by a hub business. They are thus a threat to a company that wants to establish a hub business (A).

If the hub is targeting a particular industry segment, it can be difficult to find a sufficiently large number of member companies in a suburb (B). Operating a business for thirty member companies requires almost as many resources as operating a business for three hundred member companies (B).

The physical location alone cannot attract customers to hubs. There needs to be a culture within the workplace where people interact and share knowledge with each other. There is need for someone to run the hub and establish a culture that expresses the values that the hub represents (A, B, D).

The real estate industry generally requires long-term contracts and is not very flexible. In order to facilitate the establishment of more flexible workplaces, that industry could offer more flexible contracts for premises (B). In addition, it would also be desirable to be able to rent furniture, printers, Internet access and other office equipment on more flexible terms (B).

\section{SUPPORTING TOOLS}

This section elaborates on how emerging ICT solutions can support the implementation and planning of hubs and the everyday use of, and travel to, the facilities. The combined insights obtained from the interviews and the user-centered studies are used to analyze the potential value of emerging ICT solutions in this particular context.

\section{A. Extended travel planner for finding a hub}

Travel information through travel planners has developed rapidly in recent decades. From being pure timetable services for public transport, items such as maps, navigation services and multi-modal systems have been integrated into travel planners. With increased implementation of work hubs, a demand for tools helping to physically find and communicate with the hubs will arise. This could fit well with the further development of travel planners.

Kramers [11] explored the potential value of nextgeneration traveller information systems in three phases; pre-trip, on-trip and post-trip. These three phases correspond to functionality for planning, optimizing and refining trips. An advanced travel tool could support (and change) a person's travel patterns in any of these phases, for example, by integrating with other systems and thereby being able to recommend relevant hub alternatives. The more reflective post-trip functionality can be a service that proposes work locations, based on people's travel (or activity) patterns, personal preferences and collective benefits.

The organizations surveyed in the interviews thought it would be a good idea to present their service offering in an extended travel planner. These represent one touch point where it is possible to encourage people to use a hub. A problem is that the service offering today primarily targets members and there is a lack of drop-in places for the public. Moreover, none of the organizations surveyed provides available or bookable workspaces via the Internet. Conference rooms are bookable through internet-based reservation systems, but only to members, even though they are available to the public.

If an extended travel planner were to provide information about available flexible working places in Stockholm, it would give a comprehensive overview of the market competition. The competing businesses would be more visible. Moreover, the organizations surveyed thought a social media tool connected to the information about available workplaces would be a benefit to their members. It would make it easier to collaborate if information could be obtained on who is there or not. Another opportunity is to facilitate car sharing to the hub among members.

These comments point towards some of the things that hub users must consider. One key finding in the user- 
centered research activities was also the need for holistic viewpoints [24, 28]. Transformative solutions for transportation require an understanding of the social infrastructure that affects travel patterns, for example jobs, family and friends, shopping, entertainment, public services and so on. This clearly indicates a need to integrate fragmented systems, for hubs and transportation systems to begin with, but also for systems related to other individual needs interwoven with everyday life [29]. Here, ICT platforms for connectivity, cloud services, transactions, data analytics and knowledge sharing can provide supporting mechanisms when implementing solutions that affect several interconnected challenges and opportunities. Already today, there are numerous examples of how mobile apps, sensors, open data, etc. make contextual and networked transportation services easier to realize $[30,31]$. To some degree, these systems also serves as examples of how fragmented information systems can be tied together in a comprehensible, relevant and flexible way.

\section{B. Emerging ICTs to support the workers at a hub}

The hub owners interviewed thought that providing a tool to show available and bookable workspaces would be beneficial for the workers at the hub. One obstacle was that three of the hubs $(\mathrm{A}, \mathrm{B}, \mathrm{C})$ concerned did not provide any places for the general public.

$\mathrm{W}$-work [32] in the Netherlands is an example of a service where all flexible working opportunities are gathered in one place. It provides information regarding available workplaces, conference rooms and videoconferencing equipment. It collects information from all sorts of companies that provide flexible workspaces, including office hotels, cafés and libraries. The local café can offer a price for the use of their WiFi for a longer period than it takes to drink a cup of coffee.

In terms of technology, an Internet connection is often sufficient for the professionals that utilize the hubs visited in the present study. Among the main drivers cited were being part of a community, expanding professional networks and finding a forum for knowledge exchange. However, to make the hubs an alternative for many different types of companies and professions, it is necessary to think more about the (virtual) working environment at the hubs. Many companies and professions most likely have specific needs in terms of connectivity, secure cloud services, communication services and so on.

One of the main areas in the user-centered studies was remote presence and collaboration. Hub workers employed in a large company with colleagues at different hubs around the city, or in a profession that involves meeting people or in some other way being remotely present, are groups that may need dedicated ICT tools. These could serve to support a more continuous co-presence and ambient awareness of distant colleagues and provide the opportunity to engage in ad-hoc meetings and highly interactive sessions [25].

In an increasingly networked and collaborative world, video communication and collaboration will blend in perfectly, but for the tools involved to be relevant for many different professions, new ways of interacting with them must be introduced. One of the Ericsson research projects [25] investigating these aspects was inspired by previous work around hybrid interactive surfaces [33]. By building on the nature and affordances of connected physical objects and the opportunities to use them as entry points to digital services, the project gave an example of a more immersive form of remote presence and collaboration. This is one of many examples of how emerging ICT services can make flexible workspaces an alternative for different professions.

\section{Mobility data for planning the location of a hub}

The interview study demonstrated that the location of a hub business is of critical importance. For hubs to be truly significant their location must be carefully planned in relation to transportation systems and existing travel needs such as cost, time, comfort, convenience and reliability [34-36]. One piece of valuable knowledge for urban planners can be collected through mobile phone location data, an area that several of the user-centered studies touched upon [27]. Every time a mobile phone is used or moves through a city, it transmits various kinds of information over the mobile phone network. This information can be anonymously collected and analyzed in order to understand the flows of people through the city at different times of the day [27]. Mobility data can be gathered by global positioning services such as GPS and mobile phone networks. An advantage with network-centric data collection [37] is that it also includes data originating from all mobile phones and other network-connected personal devices.

Mobility analytics can of course be combined with other data sources to get a better understanding of different types of journeys. One example from the more technical explorations is to look at speeds and locations, perhaps in combination with motion sensors in smartphones, to understand the mode of travel. The mobility data combined with other forms of crowdsourced data can provide a good picture of how hubs in new locations affect the mobility patterns, and how transportation systems may have to be adapted.

The present conditions in the transportation network can be used together with historical information to help predict and manage demands on hubs and other flexible 
workspaces. Recent work in mobility analytics has also resulted in promising methods for real-time adaptation of transportation (or other) systems [26].

\section{REFLECTION ON POTENTIAL FOR ENERGY-REDUCTIONS AND OTHER EFFECTS}

The complementary relationships between ICT and transportation, with the possibility both to decrease and to increase travel, make it difficult to estimate the environmental savings. The energy reduction potential stems from a shorter weekly commuting distance and a possible changed modal split.

This potential can be very roughly illustrated using figures for the Greater Stockholm area. The average car commute in Stockholm per day is $12 \mathrm{~km}$ each way [38] or $120 \mathrm{~km}$ weekly.

In the scenario for multiple workplaces in Figure 3, weekly commuting is divided between three workplaces. One workplace is at home (once a week). A second is situated in the local node (twice a week) and the third workplace is placed in the central node (twice a week). For the purposes of this illustration, we say that the local node is $3 \mathrm{~km}$ from home and the central node $12 \mathrm{~km}$ from home. This leads to a total commute of $60 \mathrm{~km}$, or a $50 \%$ reduction compared with the initial values. Moreover, working from a local node provides the potential to change mode of transport to more energy-efficient modes such as walking and cycling. If the individual in the example takes the bike or walks to the local node, travel by car is reduced by another 12 $\mathrm{km}$, giving an overall reduction of $60 \%$.

The scenario in Figure 3 can be seen as an intermediate scenario between today and the IT-node scenario in Figure 2. In the latter scenario the central node does not exist, so all trips go to the local node for a weakly commute of $30 \mathrm{~km}$, i.e. a $75 \%$ reduction in $\mathrm{km}$ travelled and potentially no car travel.

There are a couple of other effects connected to establishment of hubs in local nodes. E.g. there is a possibility to reduce the use of heated spaces thanks to smaller workplaces and more optimal use of premises for work. On the other hand, if the worker replaces the daily commute with driving for non-work reasons or keeps the centrally located office while using another workplace located at home or a local node, this may lead to increased emissions or energy use [37].

Effects of an entirely different kind include e.g. social effects. Face-to-face meetings between people living in the same part of the city that would not have taken place otherwise would increase. There might be a reshaping of meeting places for people living in the same area, which could lead in turn to collaborative practices and more livable communities.

\section{CONCLUDING DISCUSSION}

With the proper ICT tools and supporting infrastructure, hubs may emerge as an alternative workplace for support personnel, financial advisors and teachers - but also for doctors, mechanics and other professions that have traditionally required a physical presence. A hub could provide a flexible, employer-independent workplace near the home, family members or other important physical locations, while still maintaining much-needed social interaction. In this way, hubs could transform the physical use of the city and the urban transportation system.

The multiple workplace scenario developed in this study could act as an intermediate step in achieving the full environmental effect of telecommuting proposed in earlier studies [5]. The modified model of multiple workplaces makes use of the emerging technologies exemplified in Section IV and explores an urban organization around nodes that scarcely exist today.

In our multiple workplace examples, the energy savings potential from the use of flexible workplaces is $50-60 \%$ per car commuter, depending on how often hubs can be used and which mode of transportation is being used. The aggregated environmental effect is dependent on the proportion of citizens that can utilize the hubs. This depends in turn on how well they are integrated, not only with the transportation system but also with other social infrastructures. The demand for hubs is also driven by how work is organized - if employers demand a physical presence, the demand for hubs decreases. However, network organizations and flexible office solutions may be indications of a coming demand for hubs.

There are also wider systems effects. For example, working only some days a week from a central node makes it less important to live near the main office, and this could lead to longer trips when actually travelling, or to a switch towards abandoning the central workplace altogether.

Energy saving is not the focus of existing hub organizations and the workers involved seem instead to be looking for social interactions or improved quality of life due to less commuting. Positive environmental effects can still be achieved, although this will require a holistic view of people's transportation needs, whether work-related or leisure-related.

The quality of the supporting information systems will be very important for the future of hubs. Proper use of next-generation traveller information systems and other emerging technologies can provide the necessary 
integration between systems to understand synergy effects, optimize travel routes and access hubs based on personal preferences, thus offering a physical and virtual work environment that makes hubs a relevant alternative for more professions.

\section{REFERENCES}

[1] A. Toffler, The Third Wave, Morrow, New York, 1980. [2] P.L. Mokhtarian, A Typology of Relationships between Telecommunications and Transportation, Transport Res aPol, 24 (1990) 231-242.

[3] S.J. Marvin, Green Signals - the Environmental-Role of Telecommunications in Cities, Cities, 11 (1994) 325-331.

[4] I. Salomon, Telecommunications and Travel Relationships - a Review, Transport Res a-Pol, 20 (1986) 223-238.

[5] M. Höjer, Telecommunicators in the multinuclear city., in: Snickars F, Olerup B, P. L-O (Eds.) Reshaping Regional Planning, Aldershot, Ashgate, 2001.

[6] O. Wärneryd, Folk rör sig med tiden, in: I.M.U. (red) (Ed.) Bor och Jobbar vi annorlunda med data- och teleteknik, Teldok, Stockholm, 1990.

[7] B. Brown, K. O'Hara, Place as a practical concern of mobile workers, Environment and Planning A, 35 (2003) 1565-1587.

[8] Spaces, (2014) Retrieved 12/6, 2014 from http://www.spaces.nl

[9] United Spaces, (2013) Retrieved 7/3 2013 from http://www.unitedspaces.se/

[10] WeWork, (2013). Retrieved 22/12 2013 from https://www.wework.com

[11] A. Kramers, Designing next generation multimodal traveler information systems to support sustainability oriented decisions, Environ Modell Softw, 1-11 (2014).

[12] Rejseplanen, (2014), Retrieved 7/3 http://www.rejseplanen.dk

[13] Trafiken.nu, (2014), Retrieved 20/1, 2012, from

http;//reseplanerare.trafiken.nu and Itunes appstore.

[14] Transport Direct, (2014), Retrieved 20/1 2012, from http://www.transportdirect.info

[15] M. Höjer, Ökad Tillgänglighet och minskat resande, in, 1998.

[16] W.J. Mitchell, Me++ The cyborg self and the networked city, The MIT Press, Cambridge, Massachusetts, USA \& London, UK, 2004.

[17] M. Höjer, A hundred nodes in the Stockholm region: a simple calculation of the effects on commuting, Environ Plann B, 29 (2002) 197-217.

[18] Hub Stockholm, (2013), Retrieved 7/3, 2013, from http://stockholm.impacthub.net

[19] Kolonien, (2013), Retrieved 26/3 2013, from http://www.kolonien.se

[20] Coffice, (2013), Retrieved 26/3, 2013, from http://www.coffice.coop

[21] Ekensbergskyrkan, (2013), Retrieved 26/3, 2013, from http://www.missionskyrkan.se/ekensbergskyrkan

\footnotetext{
We gratefully acknowledge the support for the TRACS project from
}

Vinnova and the partners that participated in the project.
[22] J.F. Swoa, J.A. Zachman, Extending and formalizing the framework for information systems architecture, IBM Systems journal, 21 (1992).

[23] IDEO, Human Centered Design Toolkit, 2nd Edition, (2015), $\quad$ Retrieved 22/3 2015 from http://www.ideo.com/images/uploads/hcd_toolkit/IDEO_H CD_ToolKit.pdf

[24] M. Nyberg, M. Anneroth, J. Saros, A. Viggedal, The next age of megacities. A Networked Society report., in, 2013.

[25] M. Nyberg, C. Norlin, P. Gomez, Using physical objects to enable enriched video communication, in: MobileHCI '11 13th International Conference on Human Computer Interaction with Mobile Devices and Services., 2011.

[26] A. Garzó, I. Petrás, C. István Sidló, A. Benczúr, Realtime streaming mobility analytics. , in, 2012.

[27] Ratti C., Pulselli R. M., Williams S., F. D., Mobile Landscapes: using location data from cell phones for urban analysis., Environment and Planning B: Planning and Design., 33 (2006) 727-748.

[28] UN-Habitat, State of the world's cities 2012/2013, Prosperities of Cities, in, UN-Habitat, USA and Canada, 2013.

[29] M. Börjesson Rivera, G. Henriksson, M. Åkerlund, Getting there and back again Commuting and ICT in six cities across the globe., in, Report from the KTH Centre for Sustainable Communications Stockholm, Sweden. , 2012.

[30] Uber, (2014), Retrieved 18/2 2014, from http://www.uber.com

[31] Waze, (2014), Retrieved 18/2 2014, from http://www.waze.com

[32] W-work, (2013), Retrieved 23/8, 2013 from

http://www.w-work.nl/frontoffice/orientation

[33] D. Kirk, A. Sellen, S. Taylor, N. Villar, S. Izadi, Putting the Physical into the Digital: Issues in Designing Hybrid Interactive Surfaces. , in: BCS HCI Cambridge, 2009

[34] M. Ben-Akiva, S. Lerman, Discrete Choice Analysis, Theory and Application to Travel Demand The MIT Press, Cambridge, Massachusetts, London, England, 1985.

[35] C.G. Chorus, E.J.E. Molin, B. Van Wee, Use and Effects of Advanced Traveller Information Services (ATIS): A Review of the Literature, Transport Reviews, 26 (2006) 127-149.

[36] G. Lyons, D. , Towards integrated traveller information, Transport Reviews, 21 (2001) 217-235.

[37] V.e.a. Angelakis, Mobility modeling for transport efficiency: Analysis of travel characteristics based on mobile phone data. Mobile data for development. , in: D4D challenge., Cambridge, MA, 2013.

[38] Transport Analysis, Report 2011:3 Arbetspendling i storstadsregioner - en nulägesanalys, in, 2011: 3 ed., Trafikanalys, 2011. 